\title{
HIJOS DE CRIANZA Y CASOS TRÁGICOS. ANÁLISIS DE LOS CASOS SERENA Y VERÓNICA*
}

\author{
Carlos Arturo Duarte Martínez \\ Recibido: Junio 23 de 2015 \\ Aprobado: Noviembre 24 de 2015
}

\begin{abstract}
RESUMEN
Se aborda el estudio de los casos Serena (Italia) y Verónica (T-292 de 2004), desde los elementos configurativos del caso trágico para ver si, el segundo tiene esa condición para el Derecho constitucional colombiano. Se concluye que a partir del desarrollo que la Corte Constitucional ha realizado del principio de interés superior del niño, el derecho del hijo de crianza a permanecer con su familia de crianza puede ceder si dentro del proceso de adopción ordenado para superar su situación irregular se presenta una familia con mejores condiciones para la satisfacción de sus derechos fundamentales. Es claro entonces que en casos de hijos de crianza no se presenta una absolutización de los principios que colisionan, seña distintiva del caso trágico.
\end{abstract}

Palabras clave: Principios, Caso trágico, Hijo de crianza, Interés superior del niño, Adopción.

\section{FOSTER CHILDREN AND TRAGIC CASES. SERENA AND VERONICA CASES ANALYSIS}

\begin{abstract}
This paper proposes the study of Serena (Italy) and Veronica's cases (T292, 2004), based on the constituent elements of a tragic case, in order to

* El presente escrito presenta un resultado parcial de la investigación "La doctrina del Caso Trágico en la jurisprudencia de tutela de la Corte Constitucional", realizada bajo la dirección del Doctor Mauricio Rodríguez Delgado.

** Abogado especialista en Derecho Público de la Universidad Autónoma de Bucaramanga (UNAB). Maestrando en Derecho constitucional de la Universidad Externado de Colombia. Miembro del Grupo de Investigación en Hermenéutica Jurídica del Centro de Investigaciones "Laureano Gómez Serrano", del que es su asistente académico.cduarte3@unab.edu.co
\end{abstract}


check if the second one meets the conditions required by the Colombian Constitutional law. According to the development of the principle of the best interests of the child within the Constitutional Court, it is possible to conclude that ,the right of a family with suitable conditions to adopt foster children can prevail. It is clear, then, that in cases of foster children it is not possible to find a universilazation of principles that collide, which is the distinctive sign of a tragic case.

Key Words: Principles, Tragic case, Foster child, Interests of the child, Adoption.

\section{FILHOS ADOTIVOS E CASOS TRÁGICOS. ANÁLISE DOS CASOS DE SERENA E DE VERÓNICA}

\section{RESUMO}

Ao estudar o caso de Serena (Itália) e de Veronica (T-292, 2004) têm-se como fonte de referência os elementos constitutivos do caso trágico, a fim de identificar se o segundo se encaixa nesta categoria para o Direito Constitucional colombiano. Conclui-se que, a partir do desenvolvimento que o Tribunal Constitucional fez do princípio do interesse superior da criança, o direito do filho de criação a ficar com sua família adotiva pode ser transferido se, no processo de adoção ordenado para superar sua situação irregular, surge uma família com melhores condições para a satisfação dos seus direitos fundamentais. É claro então que, em casos de filhos adotivos, não se apresenta uma absolutização dos princípios que podem se chocar, isto é comum e caracteriza o caso trágico.

Palavras-chave: Princípios, Caso trágico, Filho adotivo, Os melhores interesses da criança, Adopção.

\section{INTRODUCCIÓN}

Los astrónomos en la búsqueda de vida por fuera de la tierra, hace algún tiempo examinaban el cielo a fin de encontrar primero los soles que sustentan los sistemas planetarios; y luego miraban alrededor para identificar planetas que los orbitaran. Ponían especial atención en la zona de habitabilidad a fin de encontrar aquellos que pudiesen albergar vida.

Dentro del proyecto de investigación "La doctrina del caso trágico en la jurisprudencia de tutela de la Corte Constitucional", adscrito al Grupo de Investigación en Hermenéutica Jurídica de la UNAB, se hace algo 
parecido. A fin de desarrollar los objetivos específicos de identificar casos trágicos en las sentencias de tutela de la Corte Constitucional y de fijar sus criterios de resolución, nos adentramos en un cielo lleno de casos difíciles. Para encontrar aquellos que son trágicos buscamos en la jurisprudencia de la Corte colombiana situaciones fácticas similares a casos que son reconocidos como tales en la doctrina y jurisprudencia extranjera.

En las siguientes líneas se hace un análisis del Caso Serena, presentado por Gustavo Zagrebelsky como un caso inconmensurable del Derecho constitucional italiano, y del Caso Verónica, resuelto por la Corte Constitucional colombiana en la Sentencia T-292 de 2004.

\section{PROBLEMA DE INVESTIGACIÓN}

De manera general, el problema que guía la investigación se contrae a resolver ¿Cuál ha sido la postura de la Corte Constitucional frente al "caso trágico"? Esto es importante debido a que el reconocimiento de la ocurrencia de casos trágicos en el Derecho lo hace un sector minoritario de la doctrina. Esta situación plantea la posibilidad de que la Corte no sea consciente de su existencia y por tanto de haberlos enfrentado los haya resuelto bajo el método de la ponderación por proporcionalidad, justo cuando se denuncia que ella es insuficiente para dar una solución razonable. Mediante el proyecto en mención pretende como objetivo general determinar si existe doctrina constitucional frente a los casos trágicos.

Así, resulta necesario establecer si el Tribunal Constitucional colombiano ha estado frente a casos trágicos y cómo los ha resuelto. En este escrito se pretende auscultar si ¿los Casos Serena y Verónica, en los cuales hace aparición la figura del hijo de crianza, reúnen las características de un caso trágico? En especial se establecerá si el caso resuelto en la T-292 de 2004 es para el Derecho constitucional colombiano un caso trágico.

De obtenerse una respuesta afirmativa, se indagara si la Corte fue consciente de la tragedia que enfrentaba al dictar su sentencia y, en todo caso, se rastrearán los argumentos dados para proteger la integridad y permanencia de los lazos afectivos de una familia de crianza que surgió de una "insólita" actuación ilegal en la que concurrieron la madre biológica y los padres de crianza de "Verónica". El texto que se entrega

1 Los padres biológicos y de crianza dieron nombres diferentes a la niña. Uno y otro fueron cambiados en la sentencia por la Corte Constitucional para proteger su identidad. Para los fines de este texto se utiliza el que corresponde al dado por los padres de crianza debido al sentido del fallo favorable a aquellos. 
se vincula con el objetivo específico de identificar en las sentencias de tutela de la Corte Constitucional tres casos trágicos

\section{HIPÓTESIS DE TRABAJO}

Se demostrará que debido a la configuración que la Corte Constitucional colombiana ha dado a la figura del hijo de crianza, en la que el derecho a que aquél permanezca con su familia de crianza está supeditado a que no se presente dentro del proceso de adopción, -con el que se debe superar la situación de ilegalidad que lo caracteriza,- otra familia que presente mejores condiciones de vida, establecer el equilibrio mínimo entre los principios en juego sí es posible, y saber si no se produce la absolutización entre ellos, como sucede en los casos trágicos.

\section{ESTRATEGIA METODOLÓGICA}

Para los anteriores fines, primero se explicarán los elementos configurativos de un caso trágico, enseguida se explicarán las similitudes entre los Casos Serena y Verónica (que no llegan a ser casos análogos), y luego se analizaran las decisiones judiciales en ellos junto con la crítica que Zagrebelsky hace al caso italiano. Finalmente se recabarán unas conclusiones.

El análisis de cada una de los casos se hace discriminando: (i) sus características fácticas, (ii) las resoluciones dictadas por los jueces de instancia, (iii) la argumentación que justifica la decisión final de la Corte, y (iv) la evaluación de la decisión a partir del "check list". Estos pasos para acometer el análisis no son caprichosos: los casos trágicos son problemas de la vida humana o social que llevados al Derecho lo hacen inaplicable como medio para alcanzar decisiones razonables. Así se reconstruye el proceso decisorio en cada resolución judicial para establecer si la tragedia invadió la actividad de la Corte Constitucional.

\subsection{RESULTADOS}

\section{1. ¿QUÉ ES UN CASO TRÁGICO?}

Como ya había se había expuesto en una anterior ocasión (Duarte \& Rodríguez, 2014), un caso trágico se distingue por tres características: 
- Existe una superposición total-total entre los supuestos de hecho de los principios que colisionan en el caso en concreto,

- Las exigencias mínimas delos principios en colisión no se pueden satisfacer. No se puede establecer una decisión que garantice un equilibrio mínimo entre los mandatos deónticos derivados de aquellos,

- Cualquier decisión conlleva eficacia total de uno de los principios en el caso en concreto, mientras que el otro resulta excluido.

La primera característica es señalada por Guastini (2007). Las más de las veces los principios chocan de manera parcial-parcial, en donde la superposición de los supuestos de hechos no es completa (como dos círculos intersecantes). En un caso trágico, la situación que se aborda cae con todos sus aspectos fácticos en los supuestos de hecho o hipótesis de conductas - por más indeterminados que sean- de dos principios que tienen mandatos contradictorios.

Por esta superposición total-total (como la de dos círculos concéntricos con el mismo diámetro), al tratar de jerarquizar uno sobre otro, es decir al buscar una decisión que traduzca la prioridad de uno de ellos se encuentra con que son inderrotables. Esto se debe a que frente al caso en concreto la consecuencia jurídica que permite realizar las exigencias mínimas de cada principio jurídico excluye al otro. Ningún principio o derecho puede ser eficaz sin que se elimine al otro.

La ponderación por proporcionalidad se caracteriza por encontrar una solución que si bien da prioridad a uno de los principios jurídicos, deja intacto los núcleos esenciales de uno y otro. Esto es lo que hace que un caso no sea trágico sino difícil. Sin embargo, obtener ese equilibrio mínimo, así llamado por Atienza (1987), y compuesto por las exigencias esenciales contrapuestas, resulta imposible.

Precisamente, la tragedia del caso trágico se deriva de no existir "forma de encontrar una solución que no sacrificará lo esencial de alguno de los dos valores" (Atienza, 1989). Es decir que el óptimo de Pareto exigencia propia de la realización de los principios (Alexy, 2002), no es predicable frente a aquellos que están inmersos en el caso trágico.

Siendo posible entonces darle eficacia sólo a un principio, el que es derrotado la pierde de manera total. De esta manera, el principio vencedor sufre un proceso de absolutización en el caso trágico, pues no da espacio para otro. 
La principal solución para los casos trágicos ha sido propuesta por Atienza (1997): se debe buscar la que cause el menor daño desde el punto de vista constitucional.

\subsection{LOS CASOS SERENA Y VERÓNICA}

La semejanza entre los Casos Serena y Verónica se limita a sus componentes fácticos y no así en las resoluciones judiciales, pues mientras los jueces italianos decidieron separar a Serena de su familia de crianza, la Corte Constitucional decidió mantener a Verónica con sus padres de crianza ordenando de manera excepcional iniciar el trámite de adopción a favor de aquellos.

Ahora bien, esto no implica una total identidad de los hechos. La semejanza de los Casos Serena y Verónica radica en las ilegalidades cometidas por los padres de crianza para iniciar y mantener (oculto de las autoridades administrativas y judiciales) los lazos afectivos y la integridad de la familia conformada con las niñas.

Así, el padre de crianza de Serena pudo ingresarla a territorio italiano después de declarar ante la embajada italiana en Filipinas que ella era su hija extramatrimonial, lo que permitió que junto con su cónyuge italiana establecieran lazos afectivos tratándola como su hija. Aunque las circunstancias en las que entró Serena a Italia nunca fueron del todo aclaradas, en la prensa y en los estrados judiciales se señaló que el matrimonio de los padres de crianza de Serena ya había adoptado legalmente a un niño filipino. Tiempo después sólo el padre viajó a Filipinas con el deseo de adoptar una niña, para que fuera su hermana. Al llegar se encontró nuevas leyes para la adopción por parte de extranjeros que exigían residir en el país por 18 meses, lo que no podría cumplir. Así él decidió registrar a Serena como hija propia, motivado además por el delicado estado de salud en que se encontraba (Ginzburg, 2010).

Los padres de Verónica, por su parte, lo hicieron por medio de un manuscrito emanado de su madre biológica que fue autenticado ante Notario en el que manifiesta no poder sostenerla y el deseo de darla en adopción a ellos para que la bauticen y la registren como su hija biológica, que fue firmado por todos ${ }^{2}$. Poco tiempo después los padres de

2 En el caso colombiano la madre biológica inició procesos judiciales y administrativos tendientes a recuperar a su hija. 
crianza de Verónica la registraron como su hija nacida de su unión material de hecho ${ }^{3}$.

Lo anterior, permitió que Serena y Verónica desarrollaran lazos afectivos fuertes y reconocieran como padres a personas con quienes no tenían vínculo biológico alguno. Ellas se convirtieron en virtud del amor, apoyo y cuidado, en hijas de crianza y aquellos en padres de crianza ${ }^{4}$.

Una vez fueron descubiertos los padres de crianza en uno y otro caso, iniciaron trámites administrativos para mantener la custodia de las niñas acudiendo a figuras jurídicas como la adopción con acogimiento ${ }^{5} \mathrm{y}$, en el caso colombiano, el hogar amigo ${ }^{6}$.

\subsection{LAS DECISIONES JUDICIALES}

\subsubsection{En el Caso Serena}

La decisión de los jueces italianos: Un Tribunal de Turín optó por desarticular la familia de crianza e incluir a Serena en el sistema estatal de protección de niños, enviándola a un orfanato italiano. Los informes señalaban el buen cuidado y el amor que le prodigaban sus padres de crianza y la buena voluntad que ellos habían tenido para llevarla a Italia; incluso compartía con un hermano de crianza de su mismo país -que sí había sido adoptado legalmente en Filipinas-. Desde luego, los jueces italianos conocían que la separación de su familia de crianza afectaría a Serena.

No se dio prioridad entonces al interés de la niña, sino que se sancionó las ilegalidades cometidas por sus padres de crianza. Persiguió esta decisión no incentivar a los mercaderes de niños, tema sobre el cual se había legislado en Italia con cierta importancia (Zagrebelsky, 2011).

La crítica de Zagrebelsky: El constitucionalista italiano no desdice sin más de la decisión judicial, que por cierto fue apoyada por un jurista de la

3 Para ello se valieron de dos testigos, como lo exige el artículo 31 del Decreto 1260 de 1970 o Estatuto del Registro del Estado Civil de las personas.

4 El hijo de crianza es una cuarta categoría dentro de la clasificación de hijos del sistema jurídico colombiano; y a diferencia del hijo matrimonial, extramatrimonial y adoptivo su origen no es legal sino jurisprudencial (Acosta y Araujo, 2012).

5 En Italia el acogimiento familiar es una etapa dentro del proceso de adopción previa a la toma decisión definitiva de dar en adopción a un niño a sus nuevos padres.

6 Como hogar amigo se ha referido la jurisprudencia a la familia que ha acogido voluntariamente a un niño para su cuidado y protección. A diferencia del hogar sustituto la estancia del niño en el hogar amigo puede superar los seis meses, por lo que se debe procurar mantenerlo en él para evitarle afectaciones. La importancia del hogar amigo radica en que a posterioridad los cónyuges pueden ser adoptantes del niño. Al respecto ver la Sentencia T-497 de 2005 
talla de Norberto Bobbio. Zagrebelsky (2011) presenta el caso desde dos posturas irreconciliables: o se deja a Serena con su familia y se remedían de cierta manera las ilegalidades, o se eliminan de modo que fueran otros padres quienes la adoptasen conforme a las reglas jurídicas italianas. Para él hay un dilema judicial claro por cuanto que "la necesidad de hacer prevalecer uno $u$ otro partido hacia inconciliables ambas posiciones... fuese cual fuese la solución elegida, se tendría que sacrificar un sentido de la historia del otro... Los valores en juego, además, conducían a una elección entre soluciones contrarias" (Zagrebelsky, 2011,p. 141).

Para él los jueces prefirieron el interés de la ley sobre el interés de la persona, lo que no comparte. En su criterio, no está del todo claro que con dejar a Serena con su familia italiana pudieran afectarse los bienes jurídicos que transgrede el tráfico internacional de niños y claramente contrariaba el principio de solidaridad pues cargaba en Serena las consecuencias de hacerle frente a dicho negocio ilícito.

La lectura de la tesis de Zabregelsky por Lariguet: Lariguet (2005) cuestiona la interpretación del principio del interés del menor que acoge Zabregelsky, pues bien podría pensarse que "esa protección ha sido interpretada correctamente [por los jueces italianos] quebrando la situación ilegal en que una niña fue objeto de mercado", y lo hace para "sugerir que todo depende [para saber si un caso es trágico o no] de cómo se reconstruya el caso y se conciba el mejor procedimiento interpretativo" (p.71).

También plantea que lo que incomoda al autor italiano es que el Tribunal de Turín prefiriere un criterio interpretativo de eficacia incierta -no queda claro en qué medida la decisión del Caso Serena va a desincentivar el tráfico de menores-, a uno de eficacia cierta-garantizar que Serena siga viviendo en felicidad con su familia de crianza-.

Según Lariguet, la postura de Zabregelsky demuestra que al igual que Dworkin tienen mayor importancia los "argumentos de principio" sobre los "objetivos políticos"?

\subsubsection{En el Caso Verónica}

Los jueces de instancia: El juzgado de primera instancia decidió dar aplicación al principio de prevalencia de los derechos del niño y proteger

7 Se refieren, respectivamente, a disposiciones que protegen bienes de interés particular y común. 
su derecho fundamental a tener una familia. En el caso en concreto señaló que pese a todas las irregularidades que permitieron que Verónica hiciera parte del seno de su familia de crianza, no podría desconocer que entre ellos habían surgido unos vínculos afectivos que deben ser protegidos. Así ordenó entregar a la niña a su familia de crianza de manera provisional como un hogar amigo, ya que el Bienestar Familiar había decidido enviarla a un hogar sustituto. Esta decisión se constituye en una medida cautelar mientras que se define la medida de protección que se da a la niña (dentro de las que está declararlo en situación de adoptabilidad).

El Tribunal de segunda instancia revocó la anterior decisión. En su argumentación tiene más peso el reproche a las ilegalidades cometidas en el proceder de los padres de crianza para quedarse con Verónica, e interpreta que el interés superior de la niña se satisface al cortar los nexos con quienes la separaron de su madre biológica y al posibilitar que se establecieran nuevamente los vínculos afectivos con toda su familia biológica. Por ello, ordenó ubicar a la niña en un hogar sustituto y no con sus padres de crianza mientras era posible su adaptación a su familia biológica.

\section{La Corte Constitucional}

\section{a. La regla jurídica}

El Caso Verónica encuentra a la Corte colombiana con un precedente consolidado sobre el hijo de crianza. Como se puede ver en Acosta y Araujo (2012) la jurisprudencia de la Corte Constitucional desde 1994 ha protegido los derechos de los niños que sin tener ningún vínculo sanguíneo o civil se han constituido de facto como partes de una familia que le da amor y protección y la que reconoce como propia, denominándolos hijos de crianza.

El principal derecho del Hijo de Crianza precisamente proviene de su mayor amenaza: ser separado de quienes lo han acogido con amor tratándolo como si fuera un hijo propio, por lo que la Corte ha establecido el derecho a no ser separado de sus padres de crianza, aun cuando su familia biológica tiempo después reclama la vuelta a su seno.

Cerca de cuatro sentencias de tutela le dieron cierta tranquilidad a la Corte Constitucional para resolver el caso Verónica pues existían reglas 
jurisprudencialmente construidas ${ }^{8}$. No era de esperar de la T-202 de 2004, entonces, una argumentación ponderativa pues ya se había dado en esas decisiones previas. Recuérdese que toda colisión de principios concluye con una regla que traduce deónticamente su orden de prioridad.

De esta manera, el trabajo argumentativo de la Corte se restringió a satisfacer su carga de transparencia al explicar el precedente y las razones que lo justifican, y su aplicación frente a la situación de Verónica. Su argumentación fue, no de otra manera, en la mayoría de sus aspectos subsuntiva.

Por lo anterior, en la medida en que ya había ponderado en situaciones anteriores sobre el hijo de crianza y tenía una regla para decidir, a ojos de la Corte Constitucional el Caso Verónica fue un caso fácil.

\begin{tabular}{|l|l|}
\hline Condiciones de aplicación o Hipótesis de Conducta & \multicolumn{1}{c|}{ Consecuencia jurídica } \\
\hline - Para que exista el hijo de crianza debe haber afecto y trato & $\begin{array}{l}\text { Debe procurarse que el } \\
\text { hijo de crianza no sea }\end{array}$ \\
amoroso entre los padres y aquél hijo, de modo que él valore & y reconozca a estos como sus padres y él igualmente sea \\
tratado como un hijo. Los vínculos que unen a la familia de & de crianza \\
crianza deben ser sólidos. & \\
- En la "traslación" del hijo de crianza de su familia \\
biológica a su familia de crianza, debe mediar la buena fe. & \\
- La estancia con su familia de crianza debe darse con la & \\
satisfacción de todos los derechos que tiene como niño. & \\
\hline
\end{tabular}

De la carga argumentativa expuesta en la Sentencia T-202 de 2004 se puede establecer la siguiente regla jurídica:

Los argumentos desarrollados a partir de principios constitucionales que sustentan la anterior regla son los siguientes:

- Todo niño tiene derecho a tener una familia y no ser separado de ella.

- Existe una presunción a favor de la familia biológica para que un hijo esté con ellos, y no con otras personas.

- Sin embargo, cuando por un lapso considerable de tiempo el hijo de crianza reconoce como padres a unas personas que no son sus progenitores "el ámbito de protección del derecho a la familia del

8 Esta línea incluía eventos de niños expositivos o sujetos a un procedimiento administrativo del Bienestar Familiar en los que se había decidido la colocación provisional en hogares sustitutos que se prolongaba a causa del olvido de las autoridades por varios años, tiempo en el cual surgía una familia de crianza. 
menor involucrado se traslada hacia su familia de crianza". (Sentencia T-202 de 2004)

- Lo anterior, no implica que la presunción desaparezca sino que deja de tener efectos. Puede que la familia biológica sea apta para criar al hijo de crianza, pero el interés superior del niño y el carácter prevalente de sus derechos hacen "que no se puedan perturbar los sólidos y estables vínculos psicológicos y afectivos que ha desarrollado en el seno de su familia de crianza”. (Sentencia T-202 de 2004)

Frente a esta regla debe hacerse ciertas precisiones: lo que se debe entender por la aplicación del principio constitucional de la buena fe en el escenario del hijo de crianza y los posibles hechos que la nieguen, no queda explicado en esta sentencia y tampoco se encuentra en los pronunciamientos previos. Sin embargo, bien puede entenderse que la Corte alude a la buena fe exenta de culpa, para cuya aplicación se requiere la consciencia de actuar con rectitud, con lealtad -elemento subjetivo-, y "la seguridad de que quien se presenta como titular del derecho o situación, realmente es titular de tal derecho o situación" -elemento objetivo-(Monroy, 2006, p. 451).

En cuanto a los efectos o consecuencia jurídica, debe indicarse que mayoritariamente la jurisprudencia del hijo de crianza de la Corte Constitucional se orienta a superar la ilegal situación que lo identifica, y en esta labor la Corte reconoce y respeta dos límites (i) la prohibición existente en el sistema jurídico colombiano de adoptar a personas determinadas,, y (ii) la competencia del Bienestar Familiar para adelantar el procedimiento de adopción, la que no puede ser usurpada por el juez de tutela ${ }^{10}$.

Así, la Corte en sus sentencias suele ordenar que mientras que el proceso de restablecimiento de derechos se lleva a cabo, el hijo de crianza permanezca con su familia de crianza en virtud de la figura del hogar amigo y cuando el menor ya ha sido declarado en condición de adoptabilidad establezca la posibilidad de que los padres de crianza aspiren a adoptarlo en iguales condiciones a otras familias que se postulen a recibir al menor, sin que pueda excluírseles por su condición de padres de crianza y por el contrario se debe valorar "los vínculos

9 Esto solo es posible cuando a quien se quiere adoptar es hijo del cónyuge o compañero permanente del adoptante (este es el caso del hijastro).

10 El Código de Infancia y Adolescencia de 2006 establece en su artículo 62, que la autoridad central en materia de adopción es el ICBF y que solo él puede desarrollar programas de adopción y las instituciones que llegue a autorizar. El artículo 107 del derogado Código del Menor y vigente al momento de la ocurrencia del Caso Verónica, regulaba la competencia para dicho trámite en los mismos términos. 
existentes y el apoyo al crecimiento del niño" a su favor dentro del proceso de adopción (T-941 de 1999).

La protección a la familia de crianza desarrollada por la jurisprudencia constitucional colombiana, entonces, se caracteriza como provisional y cautelar, y no conclusiva o definitiva. Es decir, el derecho de la familia de crianza de permanecer con el hijo de crianza en su seno no es absoluto pues dentro del proceso de adopción -que no se puede evadir-puede presentarse una familia que le brinde mejores condiciones al niño, esto es que en su trámite puede resultar un hogar que destaque por sobre el de la familia de crianza.

Las decisiones de la Corte reflejan la complejidad que entraña la decisión de determinar quiénes deben ser adoptantes, en donde se valoran diferentes razones y no únicamente las relaciones de afecto que unen al hijo con sus padres de crianza ${ }^{11}$.

Lo anterior muestra que es posible que un hijo de crianza resulte separado de su familia de crianza. Situación que debe ser justificada por la obtención de beneficios superiores con la adopción de una familia distinta a la de crianza, que la afectación representada en el dolor que genera romper los vínculos afectivos del hijo de crianza.

Así pues, resalta en las decisiones de la Corte la necesidad de que un hijo de crianza permanezca el mayor tiempo posible -cuando menos hasta que se tome una decisión definitiva sobre su futuro- en el ambiente de protección y amor que le brinda su familia de crianza.

\section{b.Aplicación al Caso Verónica}

Ahora al leer el ejercicio subsuntivo de la Corte Constitucional en la T292 de 2004 salta a la vista algo muy curioso: pareciera que la Corte implícitamente valora que los padres de crianza han actuado de buena fe, sin hacer un análisis de su conducta desde los postulados de este principio constitucional, lo cual era necesario ante las evidentes ilegalidades en que ellos incurrieron.

En los casos de los precedentes judiciales tampoco se realiza un análisis probatorio similar. En todo caso puede valorarse la falsa inscripción en el

11 Así, por ejemplo, en la Sentencia T-290 de 1995, la Corte Constitucional avaló la separación de una hija de crianza con su padre de crianza, debido a que las condiciones económicas de vida de aquél no eran suficientes para el adecuado crecimiento de la niña. 
registro civil de Verónica como hija extramatrimonial de los padres de crianza como una medida necesaria para su vinculación a los sistemas de seguridad social en salud y -en un futuro mediato- de educación, así como procurar el reconocimiento social-formal de Verónica como su hija. Todo ello representa una manifestación del cumplimiento del elemento objetivo de la buena fe exenta de culpa.

Además, aunque no fue objeto de consideración por la Corte, ya que sólo se hace referencia en los antecedentes, se contaba con una decisión judicial que reconocía la consciencia de buena fe en los padres de crianza de Verónica al iniciarse los lazos afectivos como familia de crianza. Se trata de la absolución dictada por la Fiscalía General de la Nación a favor de aquellos por el delito de obtención de documento público falso, decisión que se funda en el obrar "con error invencible que no concurría en su conducta un hecho constitutivo de la descripción típica... al cual arribaron amparados en el documento que contenía una autorización expresa de la persona que a su juicio podía decidir sobre la suerte de la niña". Esa decisión de la justicia penal refleja el cumplimiento del elemento subjetivo de la buena fe exenta de culpa, por parte de los padres de crianza de Verónica.

Desde luego, la Corte reprocha las ilegalidades que rodearon el surgimiento de los lazos afectivos de Verónica con sus padres de crianza, por lo que califica a la diligencia notarial mediante la cual se auténtico la autorización de adopción a persona indeterminada como "insólita" e "inusitada", resolviendo compulsar copias a la Procuraduría General de la Nación y a la Superintendencia de Notariado y Registro para que si lo consideran pertinente adelanten investigaciones en contra de la notaria que dio fe pública a ese documento.

Lo que sí fue de interés para la Corte y pudo verificar con amplitud -y de allí la gran extensión de la sentencia- fue el amor que se profesaban mutuamente los padres de crianza y Verónica, lo exitoso que fue su proceso de adaptación y consolidación como miembro de esa familia y el bienestar que disfrutaba con ellos. Se recaló a su vez en las afectaciones que Verónica había sufrido al ser separada de sus padres de crianza, el rechazo que tenía hacia su madre biológica, así como el desinterés demostrado de esta y demás familiares biológicos durante un considerable lapso por su bienestar y por establecer una relación familiar. 
Estas particulares circunstancias llevaron a la Corte a tomar una decisión excepcional. Si bien durante el trámite de la revisión constitucional la Corte siguió su precedente y ordenó que reintegraran a Verónica a su familia de crianza en calidad de hogar amigo, finalmente resolvió imponer como medida de protección el inicio de trámites de adopción por parte de sus padres de crianza.

Expresamente reitera el criterio expuesto en la Sentencia T-941 de 1999, que se reseñó más atrás, pero para el Caso de Verónica estableció que era necesario determinar el contenido de la medida de protección de manera inmediata, pues según los conceptos psicológicos "cualquier ruptura o perturbación adicional [con sus padres de crianza] podría incidir en forma negativa sobre su proceso de desarrollo".

A su vez estos indicaban "la alta capacidad adaptativa de Susana, que le ha permitido sobrellevar adecuadamente las separaciones traumáticas de las que ha sido objeto y reasumir plenamente su rol de hija dentro de la familia de Carmen y Roberto". Ante esta situación de excepcional recepción de Verónica en su familia de crianza y su estado actual de desarrollo físico y psíquico, para la Corte esos padres de crianza eran aptos para adoptarla.

\section{CONCLUSIONES: ¿SON CASOS TRÁGICOS?}

Si analizamos el Caso Serena a partir del precedente constitucional colombiano sobre el hijo de crianza, se tendría que un juez colombiano habría fallado en el mismo sentido de la decisión del Tribunal de Turín. En efecto, a diferencia de los padres de crianza de Verónica, los de Serena no se verían amparados por el principio de buena fe. Estos últimos conocían tantos las antiguas como las nuevas normas jurídicas filipinas de adopción y al no poder cumplir estas últimas optaron por hacer fraude, haciendo lo mismo con la normatividad italiana. Por el contrario, nada indica que los padres de Verónica actuaran por fuera de los postulados de buena fe.

Se reitera, demuestra que los Casos Serena y Verónica tan solo son parecidos pero no análogos, puesto que nada indica que los padres de crianza de esta última no actuarán amparados en la buena fe.

Dicho esto demuestra que la ausencia de la buena fe tiene la potencialidad de desarticular la familia de crianza. Pero para allanar el camino de los objetivos de este texto, en todo caso cabe preguntarse si 
¿el principio de buena fe tiene el peso suficiente para mantener vigente el vínculo que surge entre el hijo de crianza y su familia de crianza?, es decir, ¿la presencia de buena fe en la constitución de la familia de crianza es suficiente para no desarticularla?

Y al tener como fundamento la jurisprudencia de la Corte Constitucional colombiana sobre el hijo de crianza, el actuar de buena fe, inclusive, no es el elemento definitivo para dar eficacia al derecho del hijo de crianza a permanecer con sus padres de crianza. Ello porque en la aplicación de este derecho, media la valoración de otras opciones de familia para el hijo de crianza, fuera de sus padres de crianza.

Lo anterior quiere decir que las exigencias propias del principio de buena fe no tienen la entidad suficiente para negar los mandatos mínimos del principio del interés superior del niño, que ordena buscarle al hijo de crianza, como cualquier niño en situación de adoptabilidad la mejor familia posible que garantice sus derechos fundamentales.

Si se apostara por una postura cercana a la de Zagrebelsky y se optara, en aras de discusión, por excluir "el actuar de buena fe" de la hipótesis de conducta de la regla creada por la Corte Constitucional colombiana, lo cierto es que en dicho escenario tampoco se garantizaría el derecho a que hijo y padres de crianza permanecieran unidos. En ese escenario lo determinante para tomar esa decisión sería, también, identificar la familia con mejores condiciones para satisfacer sus derechos.

Como apunta la acertada crítica de Lariguet (2005) a la lectura del Caso Serena que hace Zagrebelsky, la configuración del caso trágico depende del modo en que los principios constitucionales sean interpretados.

Así, aún en el peor de los casos, a partir de la jurisprudencia colombiana pareciera que el principio de buena fe carece de la connotación jurídica para mantener a cualquier costo la integridad de la familia de crianza, pues se insiste: aún con el actuar de buena fe nada garantiza que en el proceso de adopción de los hijos de crianza no haga aparición una familia que sea una mejor opción que la familia de crianza para adoptarlo.

De este modo, el interés superior del niño frente a los casos de hijos de crianza ha sido interpretado por la Corte Constitucional como el deber de establecer cuál familia reuniría las mejores condiciones para el cuidado y el crecimiento personal durante su vida. Si dentro del proceso de 
adopción se presentara una familia mejor que la de la familia de crianza, el derecho de permanecer del hijo de crianza con aquellos debe ceder.

Todo lo anterior, allana el camino para concluir que el hijo de crianza no es en Colombia un caso trágico, debido a que la configuración del principio de interés superior del niño y de su derecho a no ser separado de su familia de crianza. En los eventos en que lleguen a colisionar no irían más allá del óptimo de Pareto, y por tanto no entrarían en el proceso de absolutización.

Las exigencias mínimas no quedarían comprometidas debido a que el derecho del hijo de crianza a permanecer con su familia y el principio de buena fe jamás podrían soslayar el principio del interés superior del niño. En la primera parte del documento se indica que en el caso trágico se desarrolla un proceso de absolutización de los principios en pugna; en los casos de hijos de crianza aquél no se da.

\section{REFERENCIAS BIBLIOGRÁFICAS}

Acosta, L. \& Araujo, L. (2012). El hijo de crianza en Colombia. Revista Escenarios Sociojurídicos, 6 .

Alexy, R. (2002). Derechos, razonamiento jurídico y discurso racional. Derecho y razón práctica, 25-41. México D.F.: Fontamara.

Atienza, M. (1987). Para una razonable definición de «razonable». DOXA. Cuadernos de Filosofía del Derecho, 4, (189-200).

Atienza, M. (1989). Sobre lo razonable en el Derecho. Revista Española de Derecho Constitucional, 27,93-110.

Atienza, M. (1997). Los límites de la interpretación constitucional. De nuevo sobre los casos trágicos. Isonomía, 6, 7-30.

Corte Constitucional. Sentencia T-290 de 1995 (M.P.: Carlos Gaviria Díaz).

Corte Constitucional. Sentencia T-941 de 1999 (M.P.: Carlos Gaviria Díaz)

Corte Constitucional. Sentencia T-292 de 2004 (M.P.: Manuel José Cepeda Espinosa) 
Corte Constitucional. Sentencia T-497 de 2005 (M.P.: Rodrigo Escobar Gil)

Duarte, C y Rodríguez, M. (2014). Prolegómenos de los casos trágicos administrativos. Revista Temas Socio-Jurídicos, $\mathrm{N}^{\circ} 67$

Ginzburg, N. (2010). Serena o la verdadera justicia. Barcelona: Acantilado.

Guastini, R. (2007). Ponderación: Un análisis de los conflictos entre principios constitucionales. Palestra del Tribunal Constitucional. 08, 2007, 631-637.

Lariguet, G. (2005). Conflictos trágicos y ponderación constitucional. En torno a algunas ideas de Gustavo Zagrebelsky y Riccardo Guastini. Diritto \& Questioni Pubbliche, $\mathrm{N}^{\circ} 5$.

Monroy, M. (2006). Introducción al Derecho. Bogotá: Temis.

Zagrebelsky, G. (2011). El derecho dúctil. Madrid: Trotta. 